\title{
APPLICATION OF THE SUPERPOSITION TECHNIQUE IN CONDUCTION HEAT TRANSFER FOR ANALYSING ARRAYS OF SHALLOW BOREHOLES IN GROUND SOURCE HEAT PUMP SYSTEMS
}

\author{
Carlos Naranjo-Mendoza ${ }^{1,2 *}$, Muyiwa A. Oyinlola ${ }^{2}$, Andrew J. Wright ${ }^{2}$, Richard M. Greenough ${ }^{2}$ \\ ${ }^{1}$ Departamento de Ingeniería Mecánica, Escuela Politécnica Nacional, Ladrón de Guevara E11-253, Quito, \\ Ecuador \\ ${ }^{2}$ Institute of Energy and Sustainable Development, De Montfort University, Leicester, LE1 9BH, United Kingdom
}

\section{INTRODUCTION}

The use of ground source heat pump (GSHP) systems for heating and cooling applications has increased notably in recent years. GSHP heating systems extract heat using ground heat exchangers (GHE), with long lengths of pipes in horizontal systems, or deep vertical boreholes (from 40 to 300 metres deep) with a higher cost of installation. On the other hand, nowadays, with the application of policies towards low energy buildings, heating loads have significantly reduced. This, plus the development of new technologies likes Solar Assisted GSHP and Dual Source Heat Pumps has helped to reduce the size of the GHE, enabling the use of arrays of shallow boreholes (up to $10 \mathrm{~m}$ ) [1]. However, studying arrays of boreholes is challenging due to the complexity of modelling the interference of multiple boreholes in a defined volume, and this complexity increases when dealing with shallow boreholes as the ground cannot be treated anymore as an undisturbed medium. In fact, the ground close to the surface is highly affected by the ambient fluctuations in the short-term (hourly or sub-hourly basis) and the long-term (seasonal variations) [2]. Accurate analytical models have not been developed for this kind of systems. Alternatively, specialised heat transfer simulation packages based on finite volumes could be employed, but the complexity and computational cost are high. In order to deal with such complexity, a superposition technique for heat transfer can be a very helpful tool. In this technique, the thermal response of a system influenced by different phenomena in different directions is obtained by superimposing the thermal response of every phenomenon in a certain point of interest [3]. This technique has been used for the study of GSHP systems previously by combining multiple analytical models [4]. However, the application of this technique for the study of shallow boreholes in which the ambient thermal impact can be superimposed has not been previously studied. In this context, this paper aims to show the application of the superposition technique for the analysis of the conduction heat transfer in arrays of shallow boreholes that are highly influenced by the ambient conditions.

\section{METHODOLOGY}

The system of analysis consists of an array of 16 shallow boreholes (1.5 metres depth) connected in series as shown in Figure 1. The model is able to evaluate the temperature of the soil at the reference point where a temperature sensor is placed. This sensor is located at 2.25 metres below the ground surface and 1 metre in the radial direction from the borehole wall of the bores B3 and B14, 2 metres from the bores B4 and B15 and 3 metres from the bores B1 and B5. In order to analyse the influence of the boreholes in the studied point, a numerical model using the finite difference method (FDM) in the radial direction was used. The boundary condition (BC) imposed was a time variable heat transfer rate from the borehole wall. As the boreholes are very shallow, a constant heat rate was imposed on each borehole and was calculated from monitored data of the flow rate and the inlet and outlet fluid temperature.

Two cases were analysed, Case $\mathrm{A}$ is the calculated temperature in the point of reference by superimposing only the heat transfer effects of the closest boreholes (B1, B3, B4, B5, B14, and B15). Hence, as seen in Figure 1, the thermal responses $\left(T_{r}\right)$ of the mentioned boreholes were included. Other boreholes were also superimposed in first calculations, but their effect was negligible, so they were removed for the final model. On the other hand, Case B is the calculated temperature in the point of reference by superimposing the heat transfer effects not only of the closest boreholes but also of the natural soil heat transfer effects by considering the top and bottom BC. The top BC is the ambient temperature while the bottom $\mathrm{BC}$ is the natural ground temperature at $3.75 \mathrm{~m}$ depth. Then, the thermal response of those $\mathrm{BCs}$ was determined by the FDM in the axial direction. 


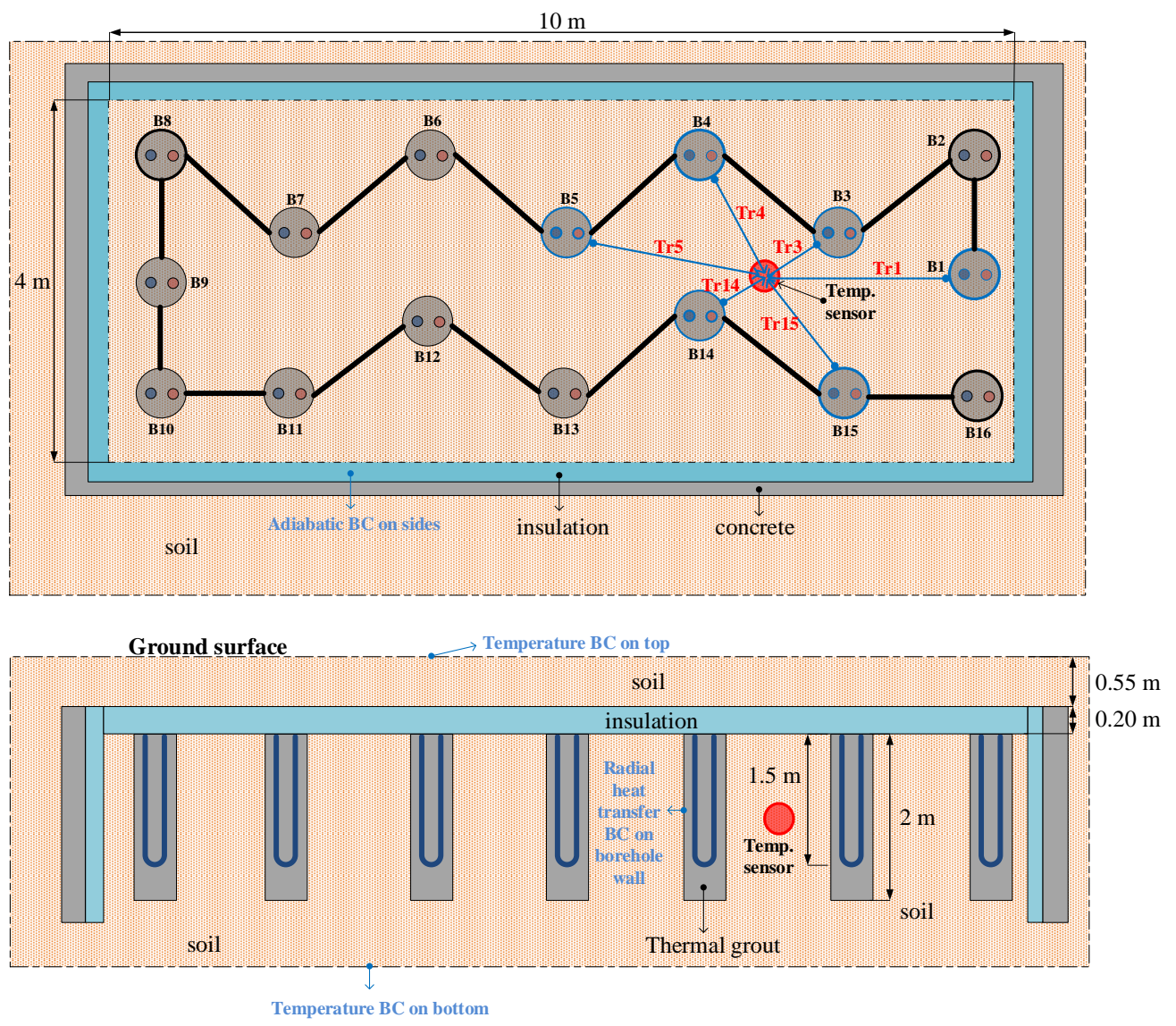

Fig. 1 Schematic of the system model and boundary conditions imposed

Equations 1 and 2 show in a simple way how the temperature of the reference point $\left(T_{r e f}\right)$ were calculated for Case $\mathrm{A}$ and $\mathrm{B}$ respectively. In these equations $T_{r_{n}}$ represents the thermal response (temperature) at the reference point caused by the borehole (Bn). In Equation 2, $T_{r_{n a t}}$ represent the thermal response at the reference point cause by the influence of the BCs at the top and bottom of the system (relative to ambient), which represent the thermal response of the natural soil.

$$
\begin{gathered}
T_{r e f_{A}}=T r_{1}+T r_{3}+T r_{4}+T r_{5}+T r_{14}+T r_{15} \\
T_{r e f_{B}}=T r_{1}+T r_{3}+T r_{4}+T r_{5}+T r_{14}+T r_{15}+T_{r_{n a t}}
\end{gathered}
$$

\section{RESULTS}

The modelling results of Case A and B were compared to experimental data from an RTD (Pt1000) located in the reference point. Temperature data were monitored from May 2016 to December 2017 on an hourly basis. In order to validate the accuracy of the models the coefficient of determination $\left(\mathrm{R}^{2}\right)$, the root mean square error (RMSE), as well as the efficiency of the model (EF) which is the residual variance of the model predictions compared to the variance of the experimental data, were determined [5]. In this case, the closer to 1 is the value of EF the more accurate is the model. Figure 2 shows the results of the model predictions for Case A and B and the experimental data. From the results, Case A is less accurate with an $\mathrm{R}^{2}$ of 0.942 , an RMSE of $1.03 \mathrm{~K}$ and an EF of 0.7896, while Case $\mathrm{B}$ has much better accuracy with an $\mathrm{R}^{2}$ of 0.966 , an RMSE of $0.79 \mathrm{~K}$ and an EF of 0.9563 . It can be noticed, in Figure 2, that the model in which the natural soil response is not superimposed lacks accuracy. This suggests that when modelling shallow geothermal systems, the natural soil temperature variation cannot be neglected, and the soil should not be treated as undisturbed. This is particularly important when designing shallow systems. It is worth highlighting that the currently available models like the infinite line source model (ILS) or the finite line source model (FLS) are the most common models to study boreholes. However, the direct application of these models should be avoided when dealing 
with shallow boreholes. Likewise, it is noted that the superposition technique in heat transfer is a simple and accurate approach that can be applied when dealing with multidimensional heat transfer problems.

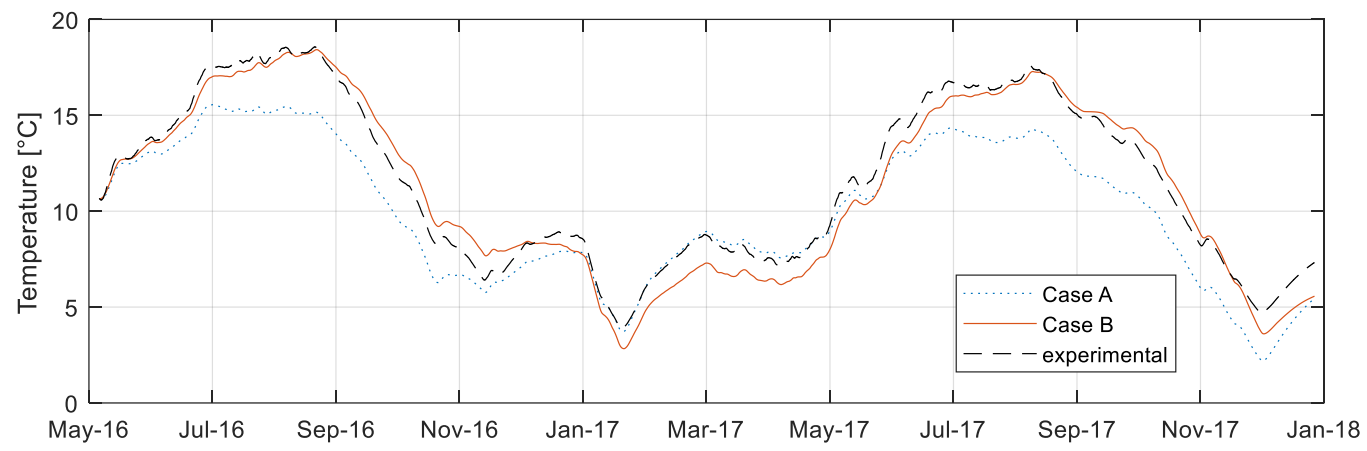

Fig. 2 Comparison of model predictions and experimental data

\section{CONCLUSIONS}

This paper aimed to show the applicability of the superposition technique in heat transfer for analysing the thermal performance of arrays of shallow boreholes considering the influence of the ambient conditions. As seen in the results, the superposition technique is a simple and accurate approach that allows assessing multidimensional heat transfer systems. In the system of this study, when neglecting the influence of the ambient conditions, the efficiency of the model (EF) and the RMSE were found to be 0.7896 and $1.03 \mathrm{~K}$, respectively. On the other hand, when considering the ambient conditions, the errors are reduced significantly to $0.9563(\mathrm{EF})$ and $0.79 \mathrm{~K}$ (RMSE). The computational cost is low, and the accuracy is well enough to perform design and long-term study of shallow boreholes. Similarly, it was evidenced that the ambient conditions cannot be neglected when studying shallow geothermal systems as the consideration of an undisturbed ground leads to significant errors.

\section{ACKNOWLEDGMENT}

The authors of this publication gratefully acknowledge De Montfort University, Caplin Homes and Vaillant UK for their support in this research.

\section{REFERENCES}

[1] M. Cimmino and P. Eslami-Nejad, "A simulation model for solar assisted shallow ground heat exchangers in series arrangement," Energy Build., vol. 157, pp. 227-246, 2017.

[2] C. Naranjo-Mendoza, A. J. Wright, M. A. Oyinlola, and R. M. Greenough, "A comparison of analytical and numerical model predictions of shallow soil temperature variation with experimental measurements," Geothermics, vol. 76, pp. 38-49, Nov. 2018.

[3] J. Taler, "Superposition Method for Multidimensional Heat Conduction Problems," in Encyclopedia of Thermal Stresses, Dordrecht: Springer Netherlands, 2014, pp. 4708-4718.

[4] M. Li, P. Li, V. Chan, and A. C. K. Lai, "Full-scale temperature response function (G-function) for heat transfer by borehole ground heat exchangers (GHEs) from sub-hour to decades," Appl. Energy, vol. 136, pp. 197-205, 2014.

[5] M. Chalhoub, M. Bernier, Y. Coquet, and M. Philippe, "A simple heat and moisture transfer model to predict ground temperature for shallow ground heat exchangers," Renew. Energy, vol. 103, pp. 295-307, 2017. 